\title{
Ammonium exposure and pyruvate affect the amino acid metabolism of bovine blastocysts in vitro
}

\author{
Nicolas M Orsi ${ }^{1}$ and Henry J Leese ${ }^{2}$ \\ ${ }^{1}$ Academic Unit of Obstetrics, Gynaecology and Paediatrics, D Floor, Clarendon Wing, Leeds General Infirmary, \\ Belmont Grove, Leeds LS2 9NS, UK and ${ }^{2}$ Department of Biology, University of York, PO Box 373, Heslington, York, \\ YO10 5YW, UK
}

Correspondence should be addressed to N M Orsi; Email: n.m.orsi@leeds.ac.uk

\begin{abstract}
The accumulation of ammonium is a major artefact of in vitro embryo culture. This study has examined ammonium production and potential mechanisms of disposal in preimplantation bovine blastocysts. Embryos were produced by in vitro maturation and fertilisation of oocytes, and cultured in synthetic oviduct fluid containing amino acids and BSA (SOFaaBSA). Ammonium/urea concentrations were determined enzymatically. Amino acid appearance/disappearance 'profiles' of single blastocysts were determined at $0,1.25$ and $2.5 \mathrm{mM} \mathrm{NH}_{4} \mathrm{Cl}$ (with or without $0.33 \mathrm{mM}$ pyruvate), and with or without $10 \mathrm{mM}$ dipicolinic acid (DPCA; a glutamate dehydrogenase (GLDH) inhibitor) or $2 \mathrm{mM}$ amino-oxyacetate (AOA; a transaminase inhibitor). Free ammonium was produced at a rate of $4.281( \pm 0.362) \mathrm{pmol} / \mathrm{embryo} / \mathrm{h}$, while urea production was undetectable. The presence/absence of pyruvate affected amino acid profiles, especially alanine appearance $(P<0.001)$, glutamate disappearance $(P<0.05)$ and overall turnover (the sum of appearance and disappearance) $(P<0.001)$. GLDH inhibition with DPCA had no effect on amino acid overall disappearance, but glutamate disappearance increased, while that of arginine decreased $(P<0.05)$. The transaminase inhibitor, AOA, depressed turnover $(P<0.05)$, aspartate and glutamate disappearance, and alanine appearance. Thus, bovine blastocysts release ammonium as free ions or fix them, not as urea, but as alanine, possibly glutamine and, less likely, arginine. An active role for GLDH and transaminases in regulating blastocyst amino acid metabolism was demonstrated.

Reproduction (2004) 127 131-140
\end{abstract}

\section{Introduction}

Although preimplantation embryos can be cultured in the absence of amino acids (Caro \& Trounson 1986, Fissore et al. 1989), their inclusion in both fertilisation and culture media enhances development and blastocyst cell numbers in the mouse (Gwatkin 1966, Spindle \& Pedersen 1973, Ali et al. 1993, Gardner \& Lane 1993, Ho et al. 1995, Lane \& Gardner 1997a,b, Nakazawa et al. 1997, Biggers et al. 2000, Summers et al. 2000), cattle (Lee \& Fukui 1996), human (Devreker et al. 2001) and hamster (Kane \& Bavister 1988, McKiernan et al. 1995). Amino acids serve a variety of physiological functions, including: the synthesis of proteins and nucleotides (Epstein \& Smith 1973, Alexiou \& Leese 1992, Katchadourian et al. 1994), nutrition and energy provision (Lane \& Gardner 1997a, 1998, Gardner 1998, Houghton et al. 2002), osmoregulation (Van Winkle \& Campione 1996, Dumoulin et al. 1997, Dawson et al. 1998), protection against oxidative stress (Lindenbaum 1973, Nasr-Esfahani et al. 1992), pH regulation (Bavister \& McKiernan 1993, Edwards et al. 1998), signalling molecule biosynthesis (Wu \& Morris 1998), trophectoderm differentiation (Martin \& Sutherland 2001) and basement membrane formation between primitive endoderm and ectoderm (Biggers et al. 2000). It is not surprising, therefore, that supplementing embryo culture medium with a mixture of amino acids reduces cultureinduced metabolic perturbations and associated loss of viability in murine blastocysts (Lane \& Gardner 1998) and overcomes developmental blocks in their leporine counterparts (Liu et al. 1996). It has also been suggested that in vitro produced embryos should be exposed to amino acids as early as the oocyte stage, as this increases oocyte maternal mRNA levels and promotes preimplantation development (Watson et al. 2000). In support of this opinion, it is notable that a brief exposure of zygotes to amino acid-free conditions depresses their developmental capacity and blastocyst cell numbers (Gardner \& Lane 1996).

Exogenous amino acid consumption and incorporation by preimplantation murine and bovine embryos increases 
throughout development, particularly after the 8-cell and compaction stages (Tasca \& Hillman 1970, Brinster 1971, Epstein \& Smith 1973, Kaye et al. 1982, Partridge \& Leese 1996). Although beneficial effects on preimplantation development may be obtained through the addition of amino acids in vitro, their spontaneous breakdown above that resulting from metabolic deamination can compromise development through increases in ammonium concentration (Gardner \& Lane 1993, Katchadourian et al. 1996). Exposure of ruminant and rodent preimplantation embryos to ammonium results in reduced intracellular $\mathrm{pH}$, depressed oxidative phosphorylation (Lane et al. 2002), decreased blastocyst cell number (Gardner \& Lane 1993), altered developmental kinetics, fetal retardation (McEvoy et al. 1997, Sinclair et al. 1999) and exencephaly (Lane \& Gardner 1994). Intriguingly, increased ammonium production also appears to be a product of protein-free culture conditions (Berg et al. 2002). In the bovine embryo, ammonium toxicity depends on both the concentration and the stage of development during which exposure occurs. Thus, exposure to ammonium during in vitro fertilisation at modest concentrations in the range $29-88 \mu \mathrm{M}$ improves subsequent development, whilst exposure during preimplantation culture at any concentration is detrimental (Hammon et al. 2000a).

The mechanism(s) by which ammonia is detrimental or beneficial - to gametes and embryos is unclear. Gardner and Lane (1993) have proposed that ammonia may mediate its adverse effects through a decrease in the concentration of $\alpha$-ketoglutarate, by promoting its conversion to glutamate. This would result in a reduction in flux through the tricarboxylic acid (TCA) cycle and reduce ATP production. Hammon et al. (2000a) suggest that this could limit ATP production post compaction consistent with the observed decrease in blastocyst (production) rate. These authors have also suggested that the vulnerability of the embryo after compaction may be due to the accumulation of ammonium in the blastocoel fluid through $\mathrm{Na}^{+} / \mathrm{K}^{+}$ ATPase and $\mathrm{Na}^{+} / \mathrm{K}^{+} / 2 \mathrm{Cl}^{-}$cotransporter activity. To overcome these problems in vitro, Lane and Gardner (1995) devised a technique for the in situ enzymatic removal of ammonium in culture, which increased murine blastocyst cell number, implantation rate, fetal development and weight after transfer.

Stress due to exposure of preimplantation embryos to excess ammonium may also occur in vivo, particularly in domestic ruminants. This occurs when animals consume excess rapidly degradable nitrogen in the absence of readily fermentable carbohydrate (e.g. as found in spring pasture), or when feed is supplemented with excess urea (McDonald et al. 1995, McEvoy et al. 1997, Sinclair et al. 1999). Urea is hydrolysed by the urease activity of rumen microorganisms, resulting in the production of ammonium (McDonald et al. 1995). In this case, the rumen microflora cannot maximise microbial protein synthesis from dietary nitrogen, urea or ammonium. Furthermore, dietary protein may also be deaminated and used as a microbial energy source, thereby releasing even larger amounts of ammonium into the circulation and increasing the risk of toxicity before it is converted to urea and removed by the kidneys (McDonald et al. 1995, Papadopoulos et al. 2001). Effects on fertility are particularly evident when such dietary changes are implemented around the time of mating or insemination (Papadopoulos et al. 2001, Dawuda et al. 2002). Whether elevated systemic concentrations of ammonia/ammonium $(\mathrm{pKa}=9.24)$ or urea in ruminants reduce embryo survival by disrupting the follicular, oviductal and/or uterine environments remains a topic of discussion (Fahey et al. 2001, Papadopoulos et al. 2001, Kenny et al. 2002). Nonetheless, it has been demonstrated that cattle with increased circulatory levels of urea had altered uterine fluid composition, decreased uterine $\mathrm{pH}$ and reduced conception rates (Papadopoulos et al. 2001). Despite having no effect on ovulation rate (Fahey et al. 2001), elevated systemic urea adversely affects oocytes and/or the follicular environment, and leads to reduced embryo development and quality, in terms of disrupted blastocyst metabolism, possibly through alterations in reproductive tract pH (McEvoy et al. 1997, Hammon et al. 2000b, Fahey et al. 2001, Papadopoulos et al. 2001, Dawuda et al. 2002). This may affect embryos in the long-term through 'reprogramming' during the earliest stages of embryo development (McEvoy et al. 1997, Kwong et al. 2000).

The mechanism(s) by which early embryos dispose of ammonium has been little investigated. Partridge and Leese (1996) and Donnay et al. (1999) suggested that pyruvate, after transamination to alanine, may potentially be used as an ammonium sink, thereby preventing the build-up of ammonium ions in the culture medium. The possibility that embryos (as undifferentiated cells) possess the urea cycle, localised in the adult to the liver, has never been examined.

In order to study the effects of ammonium in bovine blastocysts, we have: (i) measured ammonium production during embryo culture; (ii) tested whether embryos produce urea; (iii) investigated the effects of ammonium loading on blastocyst amino acid metabolism in the presence and absence of pyruvate, over a range of ammonium concentrations; and (iv) examined the metabolic effect(s) of inhibiting glutamate dehydrogenase $(\mathrm{GLDH})$ and transaminase enzymes in general.

\section{Materials and Methods \\ Culture of bovine embryos}

All chemicals were purchased from Sigma, Poole, Dorset, UK, unless otherwise specified. Cattle embryos were generated by in vitro maturation and fertilisation of oocytes aspirated from abattoir-derived ovaries, as previously described (Thompson et al. 1996). Briefly, oocyte-cumulus complexes were matured for $24 \mathrm{~h}$ in tissue culture medium 199 supplemented with $10 \%$ fetal calf serum, $1 \mu \mathrm{g} / \mathrm{ml}$ 
oestradiol, $10.9 \mathrm{ng} / \mathrm{ml}$ fibroblast growth factor, $0.47 \mu \mathrm{g} / \mathrm{ml}$ epidermal growth factor, $0.025 \mathrm{IU}$ luteinising hormone (Ferring Pharmaceuticals, Slough, Berks, UK), $0.025 \mathrm{IU}$ follicle-stimulating hormone (Ferring Pharmaceuticals), $24 \mu \mathrm{g} / \mathrm{ml}$ apo-transferrin and $1 \mathrm{mM}$ pyruvate. Fertilisation for $18 \mathrm{~h}$ was performed in Fertilisation Tyrode's Albumin Lactate Pyruvate (Fert TALP) medium with $1 \times$ $10^{6} \mathrm{sperm} / \mathrm{ml}$ freeze-thawed semen from a sire of proven fertility.

Presumptive zygotes were cultured in groups of 14 in $20 \mu \mathrm{l}$ drops of synthetic oviduct fluid supplemented with amino acids and bovine serum albumin (SOFaaBSA; Tervit et al. 1972) under a mineral oil overlay at $39{ }^{\circ} \mathrm{C}$ and a humidified $5 \% \quad \mathrm{O}_{2} / 5 \% \quad \mathrm{CO}_{2} / 90 \% \quad \mathrm{~N}_{2}$ atmosphere, until allocated to their experimental groups after $168 \mathrm{~h}$ of culture in this medium.

\section{Experimental media and amino acid profiling}

We have previously determined that chronic exposure to 0.5 and $1.5 \mathrm{mM}$ ammonium chloride affects murine embryo cell number and blastocyst rate respectively, with $3.0 \mathrm{mM}$ being the highest concentration permissive to development (N M Orsi \& H J Leese, unpublished data). We therefore tested the effects of acute ammonium loading at concentrations of $0,1.25$ and $2.5 \mathrm{mM}$ on bovine embryo amino acid profiles (see below) in the presence or absence of $0.33 \mathrm{mM}$ pyruvate. Single expanding blastocysts of comparable, good morphology were selected at $168 \mathrm{~h}$ of culture and were placed in $1 \mu \mathrm{l}$ incubation drops under mineral oil at $39{ }^{\circ} \mathrm{C}$ under a humidified $5 \% \mathrm{CO}_{2}$ atmosphere for $12 \mathrm{~h}$. In order of increasing ammonium concentration (0 (control), 1.25 and $2.5 \mathrm{mM})$, and in the presence of pyruvate, 29, 27 and 19 single blastocysts respectively, had their amino acid profiles quantified. In the absence of pyruvate, 41, 20 and 18 embryos respectively, were used.

In order to examine the potential ammonium fixation and amino acid catabolic pathways in the preimplantation bovine embryo, amino acid profiles were also determined for blastocysts cultured in ammonium-free SOFaaBSA in the presence of $10 \mathrm{mM}$ dipicolinic acid (DPCA) $(n=15$ replicates), an inhibitor of GLDH, and $2 \mathrm{mM}$ amino-oxyacetate (AOA), a generic transaminase inhibitor $(n=36$ replicates) (Broeder et al. 1994, Hewitson et al. 1996).

\section{Amino acid analyses}

Spent incubation drops were diluted 1:40 with high-performance liquid chromatography (HPLC)-grade water (Fisher Scientific, Loughborough, Leics, UK) and analysed by reverse-phase HPLC on a Kontron 500 Series automated HPLC system fitted with a Jasco F920 fluorescence detector and a $4.5 \times 250 \mathrm{~mm}$ Hypersil ODS-16 column (Jones Chromatography, Hengoed, Mid Glamorgan, UK), as previously described (Houghton et al. 2002). As an internal, non-metabolisable standard to all SOFaaBSA formulations, $0.5 \mathrm{mM}$ D- $\alpha$-amino butyric acid (Sigma) was added. Using this method, it was not possible to measure proline or cysteine.

\section{Quantification of ammonium and urea production}

Early day 7 cattle blastocysts (day $0=$ fertilisation) were placed in groups of nine in $15 \mu \mathrm{l}$ SOFaaBSA for $40 \mathrm{~h}$, and allowed to undergo expansion and hatching ( $n=7$ replicates). Spent culture medium samples $(10 \mu \mathrm{l})$ were diluted 1:2.5 with sterile water and assayed for ammonium with a COBAS MIRA autoanalyser (Roche Instruments, UK) using a commercial kit (Sigma) for the quantitative enzymatic determination of ammonia. The method was based on the reductive amination of 2-oxoglutarate, using GLDH and $\mathrm{NADPH}$. The decrease in absorbance at $340 \mathrm{~nm}$, due to the oxidation of NADPH, was proportional to the ammonium concentration. Unknown concentrations were determined by reference to a standard curve.

Urea measurements were initially performed with nine early cattle blastocysts incubated in $15 \mu \mathrm{l}$ of SOFaaBSA for $40 \mathrm{~h}$ ( $n=9$ replicates). However, urea production could not be detected, so the number of embryos, their density and incubation time were therefore increased to 30 blastocysts in $15 \mu$ l for $30 \mathrm{~h}$ ( $n=6$ replicates). Spent culture drops that had contained 20 embryos/20 $\mu \mathrm{l}$, displaying a blastocyst rate of at least $20 \%$ after $192 \mathrm{~h}$ of culture, were also assayed ( $n=13$ replicates). Analyses were performed on a COBAS MIRA autoanalyser using a commercial kit (Sigma) for the quantitative enzymatic determination of urea after its conversion to ammonium by urease. The decrease in absorbance at $340 \mathrm{~nm}$, due to oxidation of $\mathrm{NADH}$, was proportional to urea concentration. Unknown concentrations were determined by reference to a standard curve.

\section{Data presentation and statistical analysis}

Ammonium and amino acid appearance/depletion were expressed in pmol/embryo/h. Amino acid profiles with increasing concentrations of ammonium in standard or pyruvate-free SOFaaBSA were compared by a mixed model nested (hierarchical) two-way analysis of variance using a general linear model to account for imbalances in the statistical design, with a post hoc Bonferroni test to determine statistical differences between individual groups. Non-parametric sets were compared by ScheirerRay-Hare tests (by ranking and cumulative $\chi^{2}$-square). The same approach was applied to comparisons with the inhibitors AOA and DPCA. Relative turnover amino acid profiles were expressed as \% turnover (see below). All percentages were arcsine log transformed for statistical analysis, and all data were \pm S.E.M.

The following terminology was adopted to describe amino acid profiles: (i) quantitative: refers to the appearance/disappearance of individual amino acids; (ii) overall appearance/disappearance refers to the sum of all amino acids appearing/disappearing; (iii) turnover refers to the sum of 'absolute' values (i.e. ignoring sign) for amino 
acid appearance and disappearance; and (iv) relative turnover is applied to appearance/disappearance profiles, expressed as a percentage of turnover on a per embryo basis, thus accounting for differences in metabolic activity between individual embryos.

\section{Results}

\section{Ammonium and urea production by bovine blastocysts}

Ammonium was produced by cattle blastocysts at a rate of $4.281( \pm 0.362) \mathrm{pmol} / \mathrm{embryo} / \mathrm{h}$ during the blastocyst expansion and hatching period. The production of urea by cattle embryos was undetectable in all samples assayed.

\section{Effects of pyruvate and ammonium on bovine blastocyst amino acid profile}

Amino acid 'appearance' data were assigned positive values, while 'disappearance' data were given negative values. The presence or absence of pyruvate affected the quantitative profiles of histidine, glycine, tryptophan $(P<0.05)$ and alanine $(P<0.001)$, as well as overall amino acid appearance and turnover $(P<0.001)$. By contrast, ammonium addition affected the profile of asparagine $(P<0.05)$ and valine $(P<0.001)$, whereas that of aspartate and glutamate $(P<0.05)$ was affected by both ammonium and pyruvate. Overall quantitative amino acid disappearance, and the profiles of serine, glutamine, isoleucine, leucine and lysine were all unaffected by either ammonium or pyruvate. These data are illustrated in Table 1.

While overall quantitative amino acid disappearance was not affected by the presence of pyruvate or ammonium $(-12.165 \pm 1.081$ to $-19.151 \pm 2.317 \mathrm{pmol} / \mathrm{embryo} / \mathrm{h}$ range), overall quantitative appearance was significantly decreased in the absence of pyruvate in the medium $(P<0.01)$. In particular, the $1.25 \mathrm{mM}$ ammonium pyruvate group appearance was significantly higher than that of the pyruvate-free control $(14.927 \pm 1.249$ and $9.500 \pm$ $0.967 \mathrm{pmol} / \mathrm{embryo} / \mathrm{h}$ respectively; $P<0.05$ ), while none of the other values differed significantly. Amino acid turnover was significantly reduced by the absence of pyruvate $(P<0.05)$ (Fig. 1).

The presence/absence of pyruvate affected the relative turnover profiles of aspartate, serine, alanine $(P<0.001)$, glycine, tryptophan $(P<0.01)$ and isoleucine $(P<0.05)$. Ammonium loading affected histidine profile $(P<0.05)$. The methionine profile $(P<0.01)$ was affected by both parameters. Relative turnover profiles of glutamate, asparagine, glutamine, threonine, arginine, tyrosine, valine, phenylalanine, leucine and lysine were all unaffected by either ammonium or pyruvate (Table 2). Relative turnover, overall appearance and disappearance were also unaffected by these compounds (ranges of $40.665 \pm 6.469$ to $55.432 \pm 2.968$ and $44.568 \pm 2.968$ to $59.335 \pm 6.469$ respectively). threonine, arginine, tyrosine, methionine, phenylalanine,

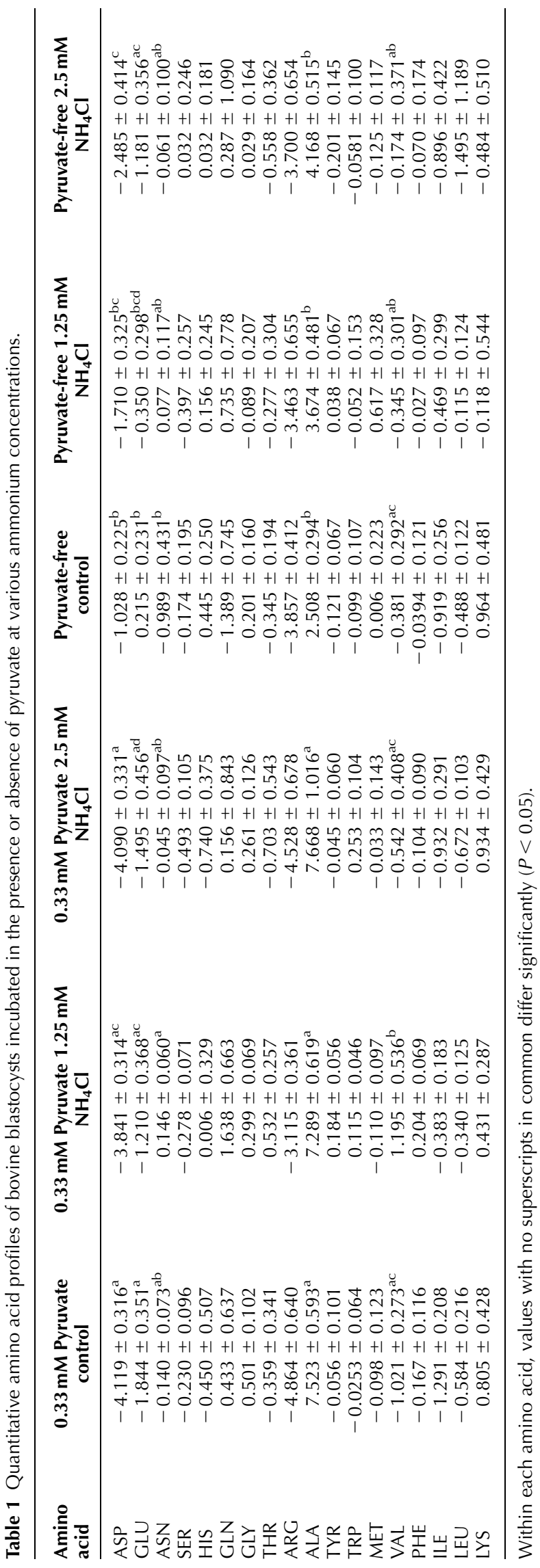

Reproduction (2004) 127 131-140 


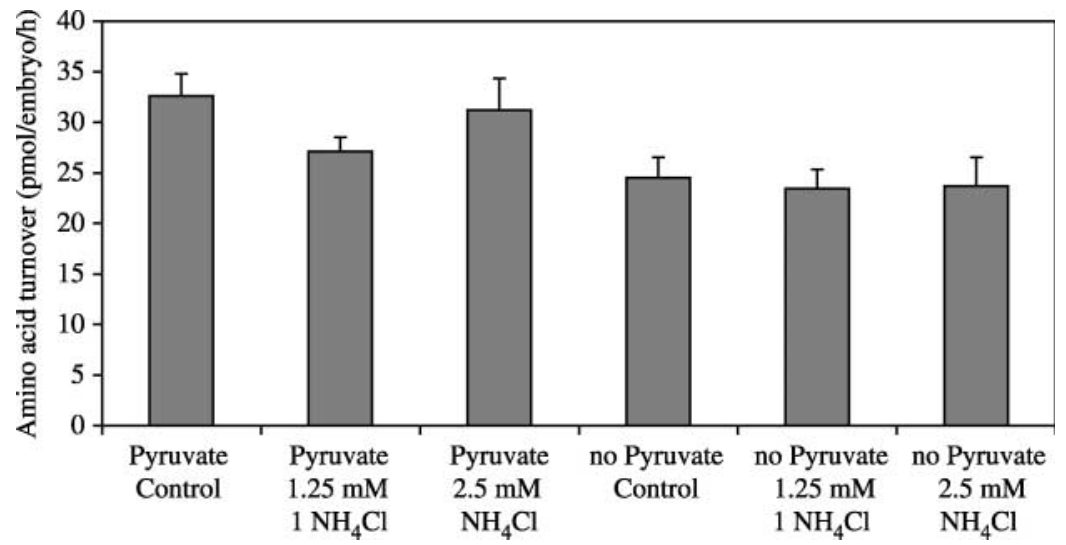

Figure 1 Amino acid turnover of bovine blastocysts incubated in the presence or absence of pyruvate at various ammonium concentrations.

\section{Effects of DPCA and AOA on bovine blastocyst amino acid profile}

Quantitatively, DPCA affected the appearance/disappearance of glutamate, glutamine, threonine, arginine, valine and isoleucine, while AOA affected the appearance/disappearance of aspartate, glutamate, serine, glycine, alanine, valine and isoleucine $(P<0.05)$ (Table 3$)$. Overall appearance with $10 \mathrm{mM}$ DPCA was significantly higher than with $2 \mathrm{mM}$ AOA $(P<0.05)$ while control values were intermediate $(16.620 \pm 1.722,10.300 \pm 1.035$ and $13.452 \pm$ 1.249 respectively). By contrast, overall disappearance in the control group was significantly higher than with $2 \mathrm{mM}$ AOA $(P<0.05)$, while $10 \mathrm{mM}$ DPCA values were intermediate $(-19.150 \pm 2.317,-13.773 \pm 1.035$ and $-14.446 \pm 1.291$ respectively). AOA also significantly reduced overall amino acid turnover, compared with control and DPCA values (24.072 \pm 1.345 compared with $32.603 \pm 2.176$ and $31.066 \pm 2.014$ respectively) $(P<0.05)$. DPCA differed from AOA by displaying higher aspartate and glutamate disappearance, lower arginine and serine disappearance, higher glycine appearance, lower threonine appearance, and higher overall appearance $(P<0.05)$.

DPCA affected the relative turnover profiles of glutamate, histidine, arginine $(P<0.001)$, tyrosine, tryptophan, phenylalanine and isoleucine $(P<0.05)$. AOA affected the metabolism of threonine $(P<0.001)$, tryptophan $(P<0.01)$, phenylalanine and isoleucine $(P<0.05)$ (Table 4). Neither inhibitor had significant effects upon relative turnover overall appearance (control $43.327 \pm$ 3.565; $10 \mathrm{mM}$ DPCA $51.497 \pm 4.580$ and $2 \mathrm{mM}$ AOA $43.028 \pm 3.112$ ) or disappearance (control 56.673 \pm $3.565,10 \mathrm{mM}$ DPCA $48.503 \pm 4.580$ and $2 \mathrm{mM}$ AOA $56.972 \pm 3.112)$.

\section{Discussion}

We were unable to detect the formation of urea by early bovine embryos. Although such embryos are unlikely to be exposed to excessive ammonium concentrations in the maternal tract under proper herd management or in the wild, they nonetheless release free $\mathrm{NH}_{4}{ }^{+}$. The average production of $4.281 \mathrm{pmol} / \mathrm{embryo} / \mathrm{h}$ over the cavitation to hatching period is comparable to the $1.0 \mathrm{pmol} / \mathrm{embryo} / \mathrm{h}$ determined for the mouse blastocyst (Gardner \& Lane 1993), as cattle embryos are roughly four times metabolically more active than their murine counterparts (Leese \& Barton 1984, Thompson et al. 1996). Since the embryos tested were all blastocysts of comparable morphology, our observations do not preclude that ammonium production may be related not only to developmental stage, but also to embryo quality.

The overall amino acid appearance/disappearance profiles observed were similar to those reported by Partridge and Leese (1996) and Jung et al. (1998). Some amino acids were depleted from the medium while others, notably alanine, appeared. The present data indicated a significant decrease in alanine production in the absence of pyruvate, in agreement with the findings of Donnay et al. (1999). These data suggest that pyruvate can be transaminated to alanine in cattle blastocysts, thereby providing a route for the embryo to dispose of ammonia, in addition to that lost directly as $\mathrm{NH}_{4}{ }^{+}$(Fig. 2). However, there was no significant dose-response increase in alanine appearance with increasing concentrations of ammonium. This could be interpreted as meaning that alanine production is not an adaptive response geared towards detoxification of increasing concentrations of ammonium in the embryo (since the alanine transaminase reaction is not regulated (Zubay 1993)), and/or that the transamination pathway is saturated at low concentrations of ammonium. Decreases in bovine blastocyst alanine output have also been documented in instances of protein deprivation in culture (Kuran et al. 2002, Orsi \& Leese 2003). However, it is speculated that the relatively brief pyruvate starvation period will have been insufficient to alter embryo protein content/protein synthesis significantly. Glutamate may also be involved in the fixation of ammonium via its conversion to glutamine, catalysed by glutamine synthetase (Fig. 2) (Salway 1996), as observed during systemic hyperammonaemia (Stryer 1988). Quantitatively, glutamate 

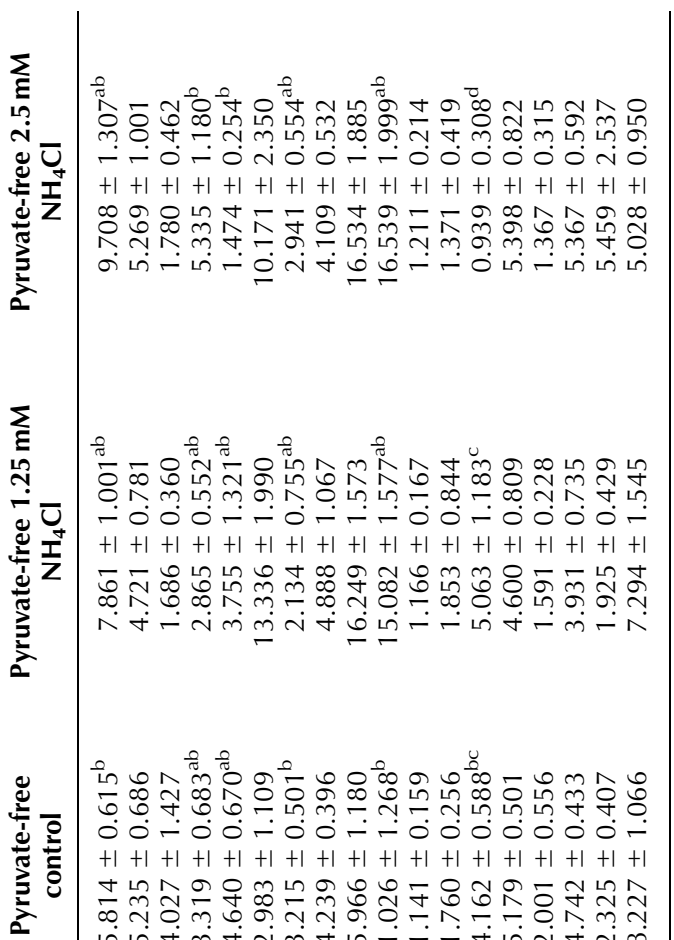
-

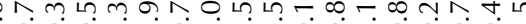
$+1+1+1+1+1+1+1+1+1+1+1+1+1+1+1+1+1+1$

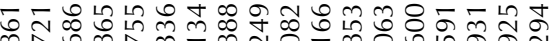
ヘுர்

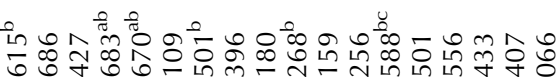

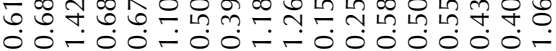
$+1+1+1+1+1+1+1+1+1+1+1+1+1+1+1+1+1+1$

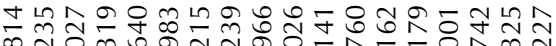
ம்

\section{๘๐+}

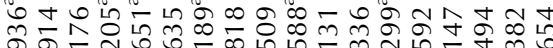
م. त.

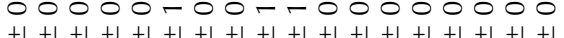

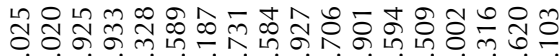
ப் ம்-

.

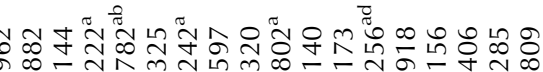

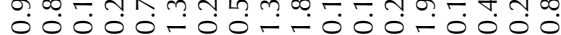

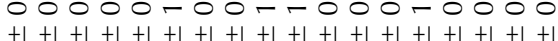
mantgmn⿻ntomman 守 In்-mó-
Table 3 Quantitative amino acid appearance and disappearance of blastocysts incubated with $10 \mathrm{mM}$ DPCA or $2 \mathrm{mM}$ AOA.

\begin{tabular}{lccr}
\hline Amino acid & Control & 10 mM DPCA & 2 mM AOA \\
\hline ASP & $-4.119 \pm 0.316^{\mathrm{a}}-4.545 \pm 0.410^{\mathrm{a}}$ & $-2.482 \pm 0.191^{\mathrm{b}}$ \\
GLU & $-1.844 \pm 0.351^{\mathrm{a}}-3.426 \pm 0.404^{\mathrm{b}}$ & $-0.619 \pm 0.272^{\mathrm{c}}$ \\
ASN & $-0.140 \pm 0.073$ & $0.189 \pm 0.059$ & $0.108 \pm 0.128$ \\
SER & $-0.230 \pm 0.096^{\mathrm{a}}$ & $0.068 \pm 0.027^{\mathrm{a}}$ & $-0.394 \pm 0.071^{\mathrm{b}}$ \\
HIS & $-0.450 \pm 0.507$ & $0.064 \pm 1.223$ & $0.078 \pm 0.399$ \\
GLN & $0.433 \pm 0.637^{\mathrm{a}}$ & $3.003 \pm 0.989^{\mathrm{bc}}$ & $1.023 \pm 0.623^{\mathrm{ac}}$ \\
GLY & $0.501 \pm 0.102^{\mathrm{a}}$ & $0.427 \pm 0.190^{\mathrm{a}}$ & $-0.027 \pm 0.129^{\mathrm{b}}$ \\
THR & $-0.358 \pm 0.341^{\mathrm{a}}$ & $1.512 \pm 0.430^{\mathrm{b}}$ & $-0.154 \pm 0.231^{\mathrm{a}}$ \\
ARG & $-4.864 \pm 0.640^{\mathrm{a}}$ & $-1.869 \pm 0.634^{\mathrm{b}}$ & $-4.407 \pm 0.370^{\mathrm{a}}$ \\
ALA & $7.523 \pm 0.593^{\mathrm{a}}$ & $6.124 \pm 0.624^{\mathrm{ab}}$ & $4.958 \pm 0.370^{\mathrm{b}}$ \\
TYR & $-0.056 \pm 0.101$ & $0.098 \pm 0.047$ & $0.010 \pm 0.108$ \\
TRP & $-0.025 \pm 0.064$ & $0.058 \pm 0.021$ & $-0.012 \pm 0.023$ \\
MET & $-0.098 \pm 0.123$ & $-0.080 \pm 0.149$ & $-0.048 \pm 0.113$ \\
VAL & $-1.021 \pm 0.273^{\mathrm{a}}$ & $0.399 \pm 0.190^{\mathrm{b}}$ & $0.072 \pm 0.484^{\mathrm{b}}$ \\
PHE & $-0.167 \pm 0.116$ & $0.063 \pm 0.063$ & $0.091 \pm 0.147$ \\
ILE & $-1.291 \pm 0.208^{\mathrm{a}}$ & $-0.260 \pm 0.169^{\mathrm{b}}$ & $-0.263 \pm 0.311^{\mathrm{b}}$ \\
LEU & $-0.584 \pm 0.216$ & $-0.641 \pm 0.169$ & $-0.316 \pm 0.311$ \\
LYS & $0.805 \pm 0.428$ & $0.993 \pm 0.309$ & $0.366 \pm 0.268$
\end{tabular}

Values with no superscripts in common differ significantly $(P<0.05)$.

Table 4 Relative turnover amino acid appearance and disappearance of bovine blastocysts incubated with $10 \mathrm{mM}$ DPCA or $2 \mathrm{mM}$ AOA.

\begin{tabular}{lccc}
\hline Amino acid & Control & $\mathbf{1 0} \mathbf{~ m M ~ D P C A}$ & $\mathbf{2 ~ m M ~ A O A}$ \\
\hline ASP & $16.908 \pm 4.545$ & $14.114 \pm 1.197$ & $11.005 \pm 0.631$ \\
GLU & $6.220 \pm 0.760^{\mathrm{a}}$ & $11.010 \pm 1.213^{\mathrm{b}}$ & $5.613 \pm 0.634^{\mathrm{z}}$ \\
ASN & $0.943 \pm 0.125$ & $0.915 \pm 0.173$ & $0.989 \pm 0.149$ \\
SER & $1.836 \pm 0.603$ & $2.467 \pm 0.461$ & $1.495 \pm 0.238$ \\
HIS & $5.839 \pm 1.042^{\mathrm{a}}$ & $12.245 \pm 2.247^{\mathrm{b}}$ & $4.317 \pm 0.984^{\mathrm{a}}$ \\
GLN & $9.372 \pm 1.413$ & $10.855 \pm 2.081$ & $8.701 \pm 1.169$ \\
GLY & $2.085 \pm 0.238$ & $1.685 \pm 0.476$ & $1.679 \pm 0.193$ \\
THR & $4.568 \pm 0.490^{\mathrm{a}}$ & $6.148 \pm 0.974^{\mathrm{a}}$ & $3.050 \pm 0.441^{\mathrm{b}}$ \\
ARG & $17.929 \pm 3.840^{\mathrm{ab}}$ & $8.092 \pm 1.785^{\mathrm{a}}$ & $19.613 \pm 1.654^{\mathrm{b}}$ \\
ALA & $30.269 \pm 7.370$ & $19.235 \pm 2.035$ & $21.689 \pm 1.112$ \\
TYR & $1.120 \pm 0.161^{\mathrm{a}}$ & $0.453 \pm 0.080^{\mathrm{b}}$ & $0.958 \pm 0.182^{\mathrm{ab}}$ \\
TRP & $0.781 \pm 0.159^{\mathrm{a}}$ & $0.283 \pm 0.059^{\mathrm{b}}$ & $0.411 \pm 0.055^{\mathrm{b}}$ \\
MET & $2.406 \pm 0.978$ & $0.812 \pm 0.393$ & $1.989 \pm 0.326$ \\
VAL & $5.242 \pm 1.555$ & $2.207 \pm 0.370$ & $5.388 \pm 0.725$ \\
PHE & $1.501 \pm 0.244^{\mathrm{a}}$ & $0.728 \pm 0.151^{\mathrm{b}}$ & $1.306 \pm 0.187^{\mathrm{b}}$ \\
ILE & $4.735 \pm 0.832^{\mathrm{a}}$ & $1.867 \pm 0.365^{\mathrm{b}}$ & $3.899 \pm 0.388^{\mathrm{b}}$ \\
LEU & $4.392 \pm 1.654$ & $2.206 \pm 0.301$ & $2.345 \pm 0.327$ \\
LYS & $6.049 \pm 1.097$ & $4.678 \pm 0.793$ & $5.553 \pm 0.612$ \\
\hline Valu & & &
\end{tabular}

Values with no superscripts in common differ significantly $(P<0.05)$.

disappearance was affected by both pyruvate and ammonium. More glutamate disappeared with increasing ammonium concentration, but only in the absence of pyruvate available for transamination to alanine. Quantitative and relative turnover profiles of serine, glycine and tryptophan in the absence of pyruvate may be accounted for by the potential of these amino acids to be converted to pyruvate (Stryer 1988, Salway 1996), providing an alternative source of this $\alpha$-ketocarboxylic acid to that supplied exogenously.

Amino acid turnover was depressed in the absence of pyruvate, most likely due to the decrease in alanine 


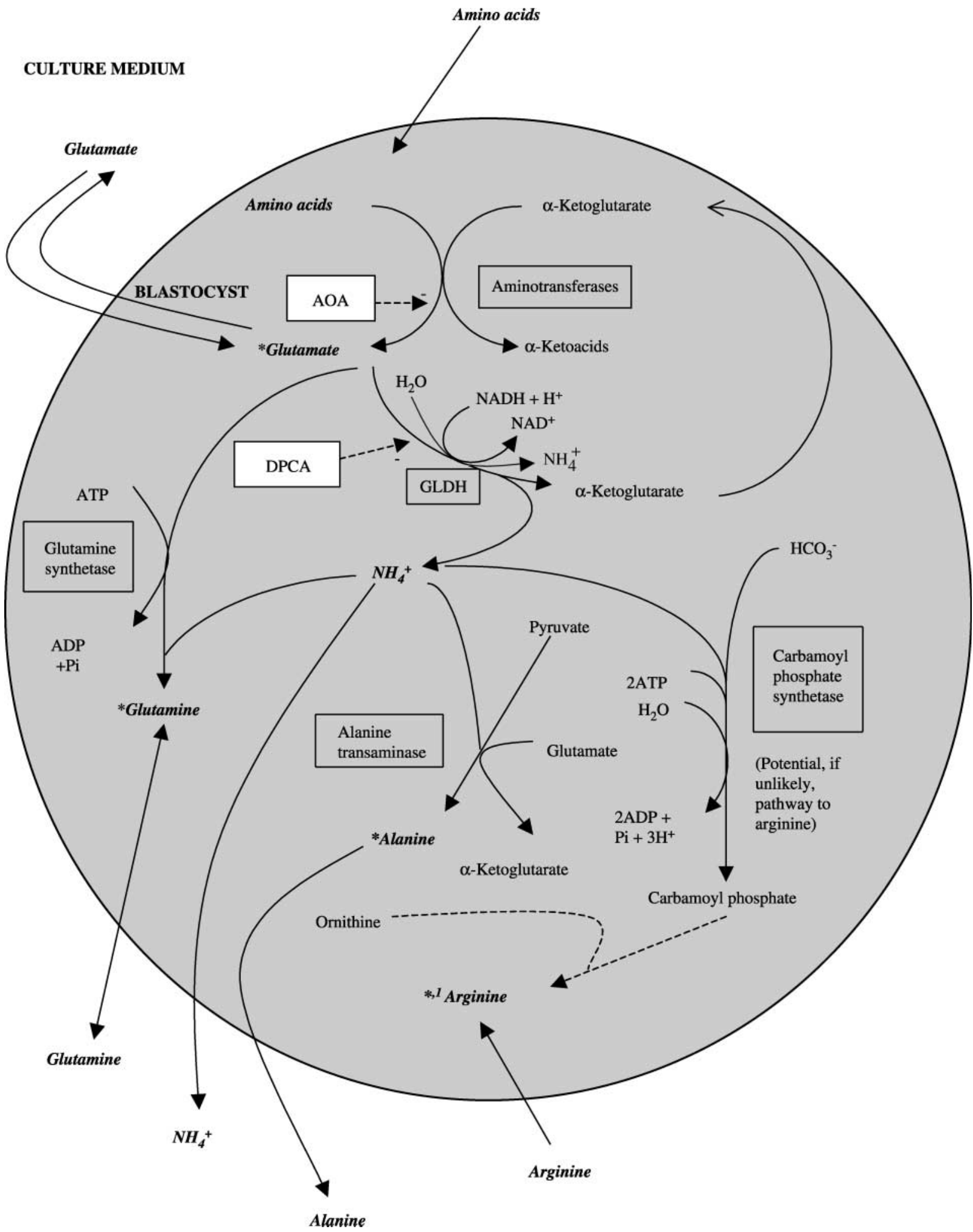

Figure 2 Schematic representation of amino acid metabolism in the bovine blastocyst including the site of action of AOA and DPCA, and the potential pathways of ammonium generation and fate (inner cell mass and trophectoderm contributions are not distinguished). *Energy metabolism, protein synthesis, potential nitrogen fixation; ${ }^{1}$ nitric oxide production, not urea production. 
output, as this was the single most important amino acid that contributed to turnover. Intriguingly, there was no evidence that embryos compensated for the absence of pyruvate by a general increase in amino acid consumption. This inability to substitute alternative oxidative substrates for pyruvate has already been noted for the early cleavage stages in the mouse (Trimarchi et al. 2000).

The amino acid profiles obtained with $10 \mathrm{mM}$ DPCA were unexpected, since GLDH catalyses the oxidative deamination of glutamate to $\alpha$-ketoglutarate, and ultimately regulates oxidative consumption of amino acids (Stryer 1988). Not only was there no reduction in the disappearance or turnover of amino acids, but glutamate disappearance itself was increased. Assuming that DPCA is a specific inhibitor for GLDH, the concentration of this compound used may have been insufficient for complete inhibition, or there could have been increased glutamate conversion to glutamine (see above). Isoleucine disappearance was lower with DPCA, both quantitatively and relative to turnover. Isoleucine catabolism, like that of other branched-chain amino acids, involves conversion of $\alpha$-ketoglutarate to glutamate through aminotransferase activity. It is unlikely that GLDH inhibition would have reduced the availability of $\alpha$-ketoglutarate, as this can be generated through TCA cycle activity. One may speculate that the reduction in isoleucine disappearance may partly have accounted for the increase in glutamate disappearance with DPCA, as the one was roughly equivalent to the other on a mole:mole basis. Less arginine disappeared in the presence of DPCA. This may have reflected the increase in glutamate disappearance under these conditions, as arginine can be derived from glutamate (via carbamoyl phosphate, citrulline and argininosuccinate), thereby acting as an ammonium sink, without the involvement of the urea-producing arginase reaction (Fig. 2). Measurement of the activities of carbamoyl phosphate synthetase, ornithine transcarbamoylase, argininosuccinate synthetase and argininosuccinase might help to clarify this possibility.

AOA is a generic transaminase inhibitor that prevents the transfer of $\alpha$-amino groups from donor amino acids to $\alpha$-ketoacids. Quantitatively, the fall in aspartate and glutamate disappearance, and alanine appearance could be explained by the inhibition of their respective aminotransferases by AOA. However, the reasons for the alterations in glycine, valine, threonine, tryptophan and phenylalanine profiles were unclear. The fall in overall amino acid appearance and turnover could have been anticipated, in view of the fall in alanine appearance, which accounted for about $25 \%$ of turnover and around $80 \%$ of appearance.

In conclusion, bovine blastocysts produce free ammonium, but can also fix amino nitrogen/ammonium, not through the production of urea, but by the pyruvatedependent synthesis of alanine and, potentially, of glutamine and arginine. Amino acid profiles of preimplantation blastocysts are affected by pyruvate availability, and, to a lesser extent, by ammonium loading. The use of aminotransferase and GLDH inhibitors also affected amino acid profiles, indicating that these enzymes play an active role in embryo amino acid catabolism.

\section{Acknowledgements}

This work was supported by the University of York and the European Commission.

\section{References}

Alexiou M \& Leese HJ 1992 Purine utilisation, de novo synthesis and degradation in mouse preimplantation embryos. Development 114 185-192.

Ali J, Whitten WK \& Shelton JN 1993 Effect of culture systems on mouse early embryo development. Human Reproduction 8 1100-1114.

Bavister BD \& McKiernan SH 1993 Regulation of hamster embryo development in vitro by amino acids. In Preimplantation Embryo Development, pp 57-72. Ed. BD Bavister. New York: SpringerVerlag.

Berg DK, Beaumont SE, Thompson JG, Phung HT \& Dunlop J 2002 Exogenous protein reduces ammonium flux from in vitro-produced bovine blastocysts. Biology of Reproduction 66 (Suppl 1) 152.

Biggers JD, McGinnis L \& Raffin M 2000 Amino acids and preimplantation development of the mouse in protein-free potassium simplex optimised medium. Biology of Reproduction 63 281-293.

Brinster RL 1971 Uptake and incorporation of amino acids by the preimplantation mouse embryo. Journal of Reproduction and Fertility 27 329-338.

Broeder JA, Smith CH \& Moe AJ 1994 Glutamate oxidation by trophoblasts in vitro. American Journal of Physiology 267 C189-C194.

Caro CM \& Trounson A 1986 Successful fertilization, embryo development, and pregnancy in human in vitro fertilization (IVF) using a chemically defined culture medium containing no protein. Journal of In Vitro Fertilization and Embryo Transfer 3 215-217.

Dawson KM, Collins JL \& Baltz JM 1998 Osmolarity-dependent glycine accumulation indicates a role for glycine as an organic osmolyte in early preimplantation mouse embryos. Biology of Reproduction 59 225-232.

Dawuda PM, Scaramuzzi RJ, Leese HJ, Hall CJ, Peters AR, Drew SB \& Wathes DC 2002 Effect of timing of urea feeding on the yield and quality of embryos in lactating dairy cows. Theriogenology $\mathbf{5 8}$ 1443-1455.

Devreker F, Hardy K, Van den Bergh M, Vannin AS, Emiliani S \& Englert Y 2001 Amino acids promote human blastocyst development in vitro. Human Reproduction 16 749-756.

Donnay I, Partridge RJ \& Leese HJ 1999 Can embryo metabolism be used for selecting bovine embryos before transfer? Reproduction, Nutrition and Development 39 523-533.

Dumoulin JC, van Wissen LC, Menheere PP, Michiels AH, Geraedts JP \& Evers JL 1997 Taurine acts as an osmolyte in human and mouse oocytes and embryos. Biology of Reproduction $\mathbf{5 6}$ $739-744$

Edwards LJ, Williams DA \& Gardner DK 1998 Intracellular pH of the mouse preimplantation embryo: amino acids act as buffers of intracellular $\mathrm{pH}$. Human Reproduction 13 3441-3448.

Epstein CJ \& Smith SA 1973 Amino acid uptake and protein synthesis in preimplantation mouse embryos. Developmental Biology 33 171-184.

Fahey J, Boland MP \& O'Callagahan D 2001 The effects of dietary urea on embryo development in superovulated donor ewes and on early embryo survival and development in recipient ewes. Animal Science 72 395-400. 
Fissore RA, Jackson KV \& Kiessling AA 1989 Mouse zygote development in culture medium without protein in the presence of ethylenediaminetetraacetic acid. Biology of Reproduction $\mathbf{4 1}$ 835-841.

Gardner DK 1998 Changes in requirements and utilisation of nutrients during mammalian preimplantation embryo development and their significance in embryo culture. Theriogenology 49 83-102.

Gardner DK \& Lane M 1993 Amino acids and ammonium regulate mouse embryo development in culture. Biology of Reproduction $48377-385$

Gardner DK \& Lane M 1996 Alleviation of the '2-cell block' and development to the blastocyst of CF1 mouse embryos: role of amino acids, EDTA and physical parameters. Human Reproduction $112703-2712$.

Gwatkin RB 1966 Defined media and development of mammalian eggs in vitro. Annals of the New York Academy of Sciences 139 $79-90$.

Hammon DS, Wang S \& Holyoak GR 2000a Effects of ammonia during different stages of culture on development of in vitro produced bovine embryos. Animal Reproduction Science 59 $23-30$.

Hammon DS, Wang S \& Holyoak GR 2000b Ammonia concentration in bovine follicular fluid and its effect during in vitro maturation on subsequent embryo development. Animal Reproduction Science 58 1-8.

Hewitson LC, Martin KL \& Leese HJ 1996 Effects of metabolic inhibitors on mouse preimplantation embryo development and the energy metabolism of isolated inner cell masses. Molecular Reproduction and Development 43 323-330.

Ho Y, Wigglesworth K, Eppig JJ \& Schultz RM 1995 Preimplantation development of mouse embryos in KSOM: augmentation by amino acids and analysis of gene expression. Molecular Reproduction and Development $41232-238$.

Houghton FD, Hawkhead JA, Humpherson PG, Hogg JE, Balen AH, Rutherford AJ \& Leese HJ 2002 Non-invasive amino acid turnover predicts human embryo developmental capacity. Human Reproduction 17 99-1005.

Jung YG, Sakata T, Lee ES \& Fukui Y 1998 Amino acid metabolism of bovine blastocysts derived from parthenogenetically activated or in vitro fertilized oocytes. Reproduction, Fertility and Development 10 279-287.

Kane MT \& Bavister BD 1988 Protein-free culture medium containing polyvinylalcohol, vitamins, and amino acids supports development of eight-cell hamster embryos to hatching blastocysts. Journal of Experimental Zoology 247 183-187.

Katchadourian C, Joly C \& Menezo Y 1994 Interactions in glycine and methionine uptake, conversion and incorporation into proteins in the preimplantation mouse embryo. Zygote 2 301-306.

Katchadourian C, Joly C \& Menezo Y 1996 Embryonal metabolism. Contraception Fertilité Sexuatité 24 650-652.

Kaye PL, Schultz GA, Johnson MH, Pratt HPM \& Church RB 1982 Amino acid transport and exchange in preimplantation mouse embryos. Journal of Reproduction and Fertility 65 367-380.

Kenny DA, Humpherson PG, Leese HJ, Morris DG, Tomos AD, Diskin MG \& Sreenan JM 2002 Effect of elevated systemic concentrations of ammonia and urea on the metabolite and ionic composition of oviductal fluid in cattle. Biology of Reproduction $\mathbf{6 6}$ 1797-1804.

Kuran M, Robinson JJ, Brown DS \& McEvoy TG 2002 Development, amino acid utilization and cell allocation in bovine embryos after in vitro production in contrasting culture systems. Reproduction 124 155-165.

Kwong WY, Wild AE, Roberts P, Willis AC \& Fleming TP 2000 Maternal undernutrition during the preimplantation period of rate development causes blastocyst abnormalities and programming of postnatal hypertension. Development 127 4195-4202.

Lane M \& Gardner DK 1994 Increase in postimplantation development of cultured mouse embryos by amino acids and induction of fetal retardation and exencephaly by ammonium ions. Journal of Reproduction and Fertility 102 305-312.

Lane M \& Gardner DK 1995 Removal of embryo-toxic ammonium from the culture medium by in situ enzymatic conversion to glutamate. Journal of Experimental Zoology 271 356-363.

Lane M \& Gardner DK 1997a EDTA stimulates the development of cleavage stage mouse embryos by inhibiting the glycolytic enzyme phosphoglycerate kinase. Biology of Reproduction $57 \quad 193$ (Abstract).

Lane M \& Gardner DK 1997b Differential regulation of mouse embryo development and viability by amino acids. Journal of Reproduction and Fertility 109 153-164.

Lane M \& Gardner DK 1998 Amino acids and vitamins prevent culture-induced metabolic perturbations and associated loss of viability of mouse blastocysts. Human Reproduction 13 991-997.

Lane M, Maybach JM \& Gardner DK 2002 Ammonium affects ICM development, metabolism, intracellular $\mathrm{pH}$, and fetal growth rates. Biology of Reproduction 66 (Suppl 1) 104.

Lee ES \& Fukui Y 1996 Synergistic effect of alanine and glycine on bovine embryos cultured in a chemically-defined medium and amino acid uptake by in vitro-produced bovine morulae and blastocysts. Biology of Reproduction 55 1383-1389.

Leese HJ \& Barton AM 1984 Pyruvate and glucose uptake by mouse ova and preimplantation embryos. Journal of Reproduction and Fertility 72 9-13.

Lindenbaum A 1973 A survey of naturally occurring chelating ligands. Advances in Experimental Medical Biology 40 67-77.

Liu Z, Foote RH \& Simkin ME 1996 Effect of amino acids and $\alpha$-amanitin on the development of rabbit embryos in modified proteinfree KSOM with HEPES. Molecular Reproduction and Development 45 157-162.

McDonald P, Edwards RA, Greenhalgh JFD \& Morgan CA 1995 Protein concentrates. In Animal Nutrition, pp 511-543. Harlow: Longman Scientific \& Technical.

McEvoy TG, Robinson JJ, Aitken RP, Findley PA \& Robertson IS 1997 Dietary excesses of urea influence the viability and metabolism of preimplantation sheep embryos and may affect fetal growth among survivors. Animal Reproduction Science 47 71-90.

McKiernan SH, Clayton MK \& Bavister BD 1995 Analysis of stimulatory and inhibitory amino acids for development of hamster onecell embryos in vitro. Molecular Reproduction and Development 42 188-199.

Martin PM \& Sutherland AE 2001 Exogenous amino acids regulate trophectoderm differentiation in the mouse blastocyst through an mTOR-dependent pathway. Developmental Biology $\mathbf{2 4 0}$ $182-193$.

Nakazawa T, Ohashi K, Yamada M, Shinoda S, Saji F, Murata Y \& Araki H 1997 Effect of different concentrations of amino acids in human serum and follicular fluid on the development of one-cell mouse embryos in vitro. Journal of Reproduction and Fertility 111 327-332.

Nasr-Esfahani MH, Winston NJ \& Johnson MH 1992 Effects of glucose, glutamine, ethylenediaminetetraacetic acid and oxygen tension on the concentration of reactive oxygen species and on the development of the mouse preimplantation in vitro. Journal of Reproduction and Fertility 96 219-231.

Orsi NM \& Leese HJ 2003 Amino acid metabolism of preimplantation bovine embryos cultured with bovine serum albumin or polyvinyl alcohol. Theriogenology 61 561-572.

Papadopoulos S, Lonergan P, Gath V, Quinn KM, Evans ACO, O'Callaghan D \& Boland MP 2001 Effect of dietary quantity and urea supplementation on oocyte and embryo quality in sheep. Theriogenology 55 1059-1069.

Partridge RJ \& Leese HJ 1996 Consumption of amino acids by bovine preimplantation embryos. Reproduction, Fertility and Development 8 945-950.

Salway JG 1996 Metabolism at a Glance. Oxford: Blackwell Science Ltd. 
Sinclair KD, McEvoy TG, Maxfield EK, Maltin CA, Young LE, Wilmut I, Broadbent PJ \& Robinson JJ 1999 Aberrant fetal growth and development after in vitro culture of sheep zygotes. Journal of Reproduction and Fertility 116 177-186.

Spindle AI \& Pedersen RA 1973 Hatching, attachment, and outgrowth of mouse blastocysts in vitro: fixed nitrogen requirements. Journal of Experimental Zoology 186 305-318.

Stryer L 1988 Biochemistry. New York: WH Freeman and Company.

Summers MC, McGinnis LK, Lawitts JA, Raffin M \& Biggers JD 2000

IVF of mouse ova in a simplex optimized medium supplemented with amino acids. Human Reproduction 15 1791-1801.

Tasca RJ \& Hillman N 1970 Effects of actinomycin D and cycloheximide on RNA and protein synthesis in cleavage stage mouse embryos. Nature 225 1022-1025.

Tervit HR, Whittingham DG \& Rowson LEA 1972 Successful culture in vitro of sheep and cattle ova. Journal of Reproduction and Fertility 30 493-497.

Thompson JG, Partridge RJ, Houghton FD, Cox CI \& Leese HJ 1996 Oxygen uptake and carbohydrate metabolism by in vitro derived bovine embryos. Journal of Reproduction and Fertility 106 299-306.
Trimarchi JR, Liu L, Porterfield DM, Smith PJS \& Keefe DL 2000 Oxidative phosphorylation-dependent and -independent oxygen consumption by individual preimplantation mouse embryos. Biology of Reproduction 62 1866-1874.

Van Winkle LJ \& Campione AL 1996 Amino acid transport regulation in preimplantation mouse embryos: effect of amino acid content and pre- and peri-implantation development. Theriogenology 45 69-80.

Watson AJ, De Sousa P, Caveney A, Barcroft LC, Natale D, Urquhart J \& Westhusin ME 2000 Impact of bovine oocyte maturation media on oocyte transcript levels, blastocyst development, cell number, and apoptosis. Biology of Reproduction 62 355-364.

Wu G \& Morris SM 1998 Arginine metabolism: nitric oxide and beyond. Biochemical Journal 336 1-17.

Zubay G 1993 Biochemistry. New York: WB Publishers.

Received 20 May 2003

First decision 28 July 2003

Revised Manuscript Received 2 September 2003

Accepted 25 September 2003 